\title{
Conceptual Design of the Space Station Combustion Module
}

Daniel P. Morilak, Dennis W. Rohn, and Jennifer L. Rhatigan

Lewis Research Center

Cleveland, Ohio

Prepared for the

33rd Aerospace Sciences Meeting and Exhibit

sponsored by the American Institute of Aeronautics and Astronautics

Reno, Nevada, January 9-12, 1995

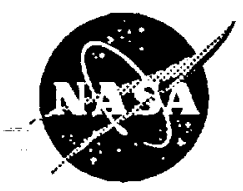

National Aeronautics and Space Administration
(NASA-TM-106788) CDNCEPTUAL OESIGN OF THE SPACE STATION COMBUSTION MODULE (NASA. Lewis Research (enter) $13 \mathrm{p}$
N95-17419

Unclas 
I $\quad-\ldots$ 


\title{
CONCEPTUAL DESIGN OF THE SPACE STATION COMBUSTION MODULE
}

\author{
Daniel P. Morilak, Dennis W. Rohn, and Jennifer L. Rhatigan \\ NASA Lewis Research Center \\ Cleveland, $\mathrm{OH}$
}

\begin{abstract}
The purpose of this paper is to describe the conceptual design of the Combustion Module for the Intemational Space Station Alpha (ISSA). This module is part of the Space Station Fluids/Combustion Facility (SS FCF) under development at the NASA Lewis Research Center. The Fluids/Combustion Facility is one of several science facilities which are being developed to support microgravity science investigations in the US Laboratory Module of the ISSA. The SS FCF will support a multitude of fluids and combustion science investigations over the lifetime of the ISSA and return state-of-the-art science data in a timely and efficient manner to the scientific communities. This will be accomplished through modularization of hardware, with planned, periodic upgrades; modularization of like scientific investigations that make use of common facility functions; and through the use of orbital replacement units (ORUs) for incorporation of new technology and new functionality.

The SS FCF is scheduled to become operational on-orbit in 1999. The Combustion Module is presently scheduled for launch to orbit and integration with the Fluids/Combustion Facility in 1999.

The objectives of this paper are to describe the history of the Combustion Module concept, the types of combustion science investigations which will be accommodated by the module, the hardware design heritage, the hardware concept, and the hardware breadboarding efforts currently underway.
\end{abstract}

"Copyright (C) 1994 by the American Institute of Aeronautics and Astronuatics, Inc.

No copyright is asserted in the United Stales under Titte 17, U.S. Code. The U.S. Govemment has a royalty-free license to exercise all rights under the copyright claimed herein for Governmental purposes. All other rights are reserved by the copyright owner."

\section{Background}

NASA Lewis Research Center (LeRC) received approval from NASA Headquarters to begin a definition study and conceptual design effort for a Modular Combustion Facility in June of 1987. The objective of the study was to assess the feasibility, effectiveness, and benefits to potential users of a modular, multi-user facility for performing combustion science and applications experiments aboard the Space Station Freedom1. Facility class hardware has been considered as an alternative to experiment specific hardware for several reasons; 1) modular, multi-user facilities can provide resources or services to users which are non-standard to space station, 2) the modular approach allows for growth in capabilities over time, 3) common subsystems developed across facilities improve maintainability and minimize logistics requirements, 4) minimizing the individual investigators experiment hardware should reduce the individual experiment development time, and 5) the facility approach can minimize cost to the overall science discipline program while maintaining operational flexibility.

A study team was formed with the purpose of accomplishing five tasks: 1) define requirements for a modular combustion facility (MCF), 2) develop design concepts, 3) perform trade studies on these design concepts, 4) develop a plan for future development, and 5) obtain independent assessment of the concept and plan. A facility project scientist from The LeRC Space Experiments Division (SED) combustion science group was chosen to work with the engineering team and to define science requirements for formulation of a concept. The process used to define the requirements started with a reference set of microgravity combustion science experiments. This set of reference experiments was an extrapolation of the (then) current microgravity combustion experiment program and was intended to represent a majority of the program with potential combustion experiments. 
This initial reference experiment list contained the following experiment types:

1. Stabilized Gaseous Combustion

2. Freely Propagating Flames

2. Freely Propagating Flaming and Smoldering Combustion in Low
Velocity Flows

4. Effects of Extinguishants on Flaming and

Smoldering Combustion

5. Pool Fires

6. Droplets Combustion

7. Metals Combustion

There were other facilities being conceptualized as well for operation on the space station, such as a containerless processing facility, a fundamental science facility, a biotechnology facility, and a fumace facility. In September of 1988 this set of reference experiments allocated to be performed in the Modular Combustion Facility was evaluated by the Combustion Science Discipline Working Group (DWG) and NASA Headquarters, and deemed to have appropriate commonality and scientific significance to require a unique facility dedicated to microgravity

combustion investigations.

Specific experimental requirements were developed for each of the above listed experiment categories in the reference set. These experiment specific requirements were then used as the basis for the LeRC team to develop a conceptual design of a Space Station Freedom based Modular Combustion Facility.

At this point in the effort, a Space Station Freedom Modular Combustion Facility Assessment Workshop was held at the Lewis Research Center. The purpose of that workshop was to obtain science and engineering assessments of the Modular Combustion Facility design and operational concepts as well as the selected microgravity combustion science requirements used to develop those concepts.

\section{1.___ Combustion Science Accommodations}

As a result of this workshop, the study team further developed the experiment specific requirements and the conceptual design of the MCF. The facility scientist continued to refine the science requirements and developed a Science Requirements Envelope Document (SRED). This document encompassed the science requirements by which the hardware concept was being developed and were specified so that individual experiment science requirements would most often fall within this envelope. The envelope included seven representative experiment requirements:

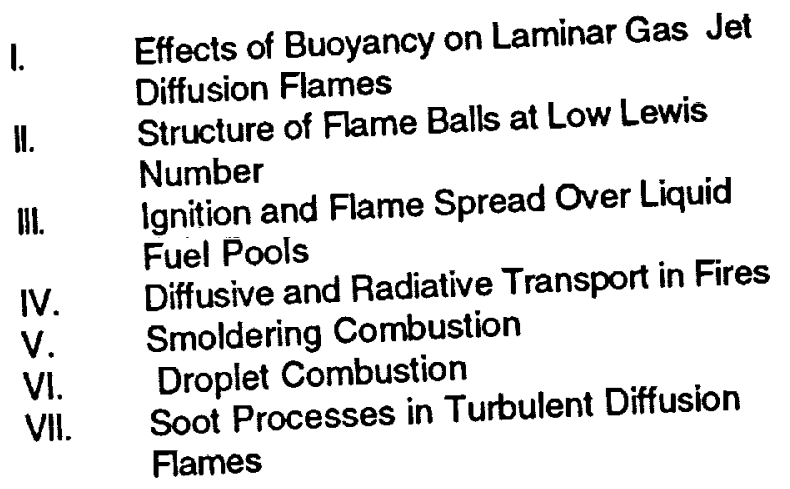

These seven experiments were proposed by Principle Investigators (PIs) in the 1990 Combustion NASA Research Announcement. The SRED is also representative of other gaseous, liquid and solid fuel experiments, such as metals combustion and spray combustion. The conceptual design effort continued by focusing on accommodating these seven experiments in the MCF. A review of the MCF conceptual design was held December of 1991. This review covered specific concepts for accommodating six of the seven representative experiments in the Combustion SRED. Another review was held in September 1992, which covered the accommodations for the seventh experiment. As a result of these reviews the concept for the MCF was approved. Also, the Combustion Science DWG reviewed this SRED and the engineering design concept and endorsed both in January 1993.

During this time the Space Station
Freedom Program was evolving to become what is currently known as the International Space Station Alpha (ISSA). Changes also occurred in the concept of the MCF in that it was now envisioned as a combined facility with the Fluid Physics/Dynamics Facility, sharing common functions, such as data handling, communications, and carrier interfaces. These combined facilities are now called the Space Station Fluids/Combustion Facility (SS FCF) which houses a Fluids Module for performing microgravity fluids science (formerly the FP/DF), and a Combustion Module for performing microgravity combustion 
science (formerly the MCF), with shared resources for both. The combustion SRED, in conjunction with fluids SRED and Space Station carrier and safety requirements will be used in the engineering specification development process for the SS FCF. As specific investigations are assigned to the SS FCF, investigation-specific requirements will be checked against the SRED's and any new requirements will either be accommodated in the system specification and the hardware design or negotiated with experiment specific development teams.

\section{Ill. Handware Henitage}

The design of the SS FCF will draw upon the design of as many previous space experiments as possible. Since the science requirements envelope includes many investigations that have previously operated on orbit or are being developed, previous development efforts will be utilized to minimize cost and schedule. The areas of heritage include diagnostics, fluid systems, combustion chamber and combustion apparatus. The design of the SS FCF Combustion Module will be based heavily on the design of the Combustion Module - $1(\mathrm{CM}-1)$ for the Microgravity Science Laboratory - 1 mission which is a Spacelab Mission scheduled to be launched in 1997. CM-1 is a derivative design from an initial concept which would have accommodated all of the classes of experiments within the Combustion SRED. CM-1 is designed to accommodate two specific investigations, Laminar Soot Processes and Structure of Flame Balls at Low Lewis Numbers. However, much of the design will be common with the SS FCF Combustion Module. The areas that will be modified are those required to interface with Space Station and to provide the flexibility to accommodate the full science envelope. Depending on project schedules and spares availability, some of the hardware components from $\mathrm{CM}-1$ may be utilized.

The SS FCF Combustion Module will also draw heavily on designs of subsystems, components and test apparatus developed at LeRC on other combustion experiment projects, many of which fall into one of the classes of experiments covered by the science envelope.

\section{Hardware Description}

The concept for the SS FCF has been developed based on the envelope of science requirements discussed in section III and those for the fluids module portion of the project. The concept is a three rack facility as shown in figure IV. 1. The right hand rack contains the hardware required to support fluid physics and dynamics experiments. The left hand rack contains the hardware required to support combustion experiments and the central rack provides core functions and system control. A Hardware Capabilities Document (HCD) is being drafted that will provide details on capabilities of the SS FCF. An Accommodations Handbook is also planned to aid currently planned and potential users in the development of experiments to use the facility. The discussion that follows will address the Core Systems and the Combustion Module. The Fluids Module concept is described in reference 3 .

The hardware in the racks fall into three groups: core systems, combustion module, and experiment specific. A detailed discussion of each of these groups follows and is shown pictorially in figures IV-2, Core Systems Diagram, and IV-3, Combustion Module Diagram .

\section{A. Core System Capabilities/Description}

The core system hardware concept is shown in figure IV-2. The core systems are the primary interface to space station systems and the crew. The core systems also provide space for, interfaces to, and control of the combustion module and experiment specific hardware. Following is a description of the various functions performed by the core systems.

Structural Support The core systems provide structural support for all of the core systems packages and the Combustion Module hardware. This support is accomplished through the use of International Standard Payload Racks (ISPR's) which mount directly into the space station U.S. Laboratory Module.

Facility Command. Control and Data Handling Facility command, control and data handling (CCDH) will be accomplished by implementing a distributed control, Versa Module Europe (VME) bus system architecture. One VME bus system will be located in the core rack to provide facility level CCDH and one will be located in the combustion rack to provide $\mathrm{CCDH}$ to the hardware located in that rack. A Fiber Distributed 
Data Interface (FDDI) system is planned for interrack communications due to the high data rates required. The $\mathrm{CCDH}$ has three interfaces with space station: a Mil-1553 B data bus, an Ethernet data bus, and a fiber optic high rate data bus. Data, including digitized and compressed video, will be stored in high volume mass storage devices until it can be downlinked to the ground.

Crew Interface The crew interface will provide a system for the crew to view sensor and video data and control the facility. This system will include a video monitor and a laptop computer.

Video Image Control and Processing

Core systems will provide for routing and

processing of video images generated by the facility. A dedicated VME card cage will be used to provide this control, and digitization and compression of images so that the images can be stored (digitization and compression of images is required so the data can be stored on a reasonably sized storage device and sent to the ground within a reasonable time).

Electrical Power Core systems will provide for conditioning, conversion and distribution of 120 VDC power provided by space station. The core rack will provide for 28 VDC and 120 VDC to the combustion rack and the combustion rack will additionally provide 5 VDC and 12 VDC.

Thermal Control Core systems will reject heat from the facility via an interface with the space station moderate temperature water system. Both the core and fluids racks will have an avionics air system tied into the water systems to provide general surface cooling. In addition, the core rack will contain heat exchanger/pump assemblies to route cooled water to specific hardware in the facility that requires large amounts of cooling. Vibration Data Processing A Space Acceleration Measurement System II (SAMS II) Remote Triaxial Sensor Electronics Enclosure (RTS-EE) will be located in the core rack to provide data processing and measurement support for the sensor head that will be located in the combustion module.

\section{B. Combustion Module Capabilities/Description}

The combustion module, as shown in figure IV-3, consists of an experiment package, a fluid supply package and an exhaust/vent package. Each of these packages, along with portions of each, will be capable of being replaced on orbit in order to upgrade and/or provide additional functionality.

Experiment Package The experiment package is the primary element of the combustion module. It is comprised of two major elements, the combustion chamber and the diagnostics mounted around the chamber. The combustion chamber is cylindrical with domed heads, has approximately 80 liters internal free volume and has a maximum design pressure of $1000 \mathrm{kPA}$. A number of window ports provide optical access to the interior of the chamber. The windows in these ports are concepted to be replaceable on orbit so that they can be tailored to the diagnostic technique using the window. An instrumentation ring and slide rails provide a standard set of interfaces inside the chamber. An Experiment Mounting Structure (EMS), which is unique to the particular science investigation being conducted, mounts within the chamber on these slide rails and interfaces to the instrumentation ring for gases, power, command, control and data. One end dome of the combustion chamber will be opened on orbit for access to the inside of the chamber and installation of EMSs. A glovebox can be provided which interfaces with the chamber, if required, to maintain containment of materials within the chamber while the door is open,

There are three types of diagnostics mounted around the chamber: optical, chemical and sensor. The optical diagnostics are mounted on an optical plate that allows for reconfiguration on orbit, and the combustion event is viewed through windows in the combustion chamber. These windows are of various size and are chosen to be optically compatible with the diagnostic tool which will utilize that viewport. The chemical diagnostics consist of a gas chromatograph used to sample the contents of the combustion chamber to determine the products of combustion. The sensor diagnostics provide information such as chamber pressure, chamber wall temperature, and temperatures of gases flowing into the chamber. A SAMS II sensor head will also be mounted near the chamber to measure the vibration disturbances during test runs.

The standard optical diagnostics planned for the facility are two orthogonal intensified black and white video cameras, two orthogonal standard color video cameras, soot volume fraction measurements and soot temperature measurements. Filters and lenses can be changed to provide a variety of field of views and resolution 
combinations for selected experiments. Some of the other diagnostics that are being studied to determine if they can be accommodated are color schlieren imaging, infrared imaging, ultraviolet intensified imaging, color intensified imaging. infrared intensified imaging, laser doppler velocimetry, and both gas and liquid phase particle imaging velocimetry.

Fluid Supply Package The fluid supply package provides all gaseous fuels, diluent and oxygen required to perform the envelope combustion experiments. The package consists of gas storage and gas flow control functions. Pure gases and nominal mixtures will be stored in bottles at pressures up to $20 \mathrm{MPa}$. Some of the gases will be stored as pressurized liquids. The combustion module will utilize nitrogen provided by space station. The storage bottles will be designed to be easily changed out on-orbit, for resupply, with filled ones that have been brought to the space station. The flow control will allow for conversion of any liquified fuels or diluents back to a gaseous state, mixing of gases to the concentrations required, filling of the combustion chamber to prescribed pressures, flowing of gases into the combustion chamber during combustion and venting or purging of the fluid systems and chamber. In addition the system will provide any controls of the gases required to assure the safety of the FCF and crew.

Exhaust $/$ ent Package The exhaust vent package is the interface from the experiment and fluid supply packages to the space station vent system and allows the fluid system and combustion chamber to be evacuated. The primary function of this package is to process the gases being vented so they meet the interface requirements of space station. The package includes a recirculation loop and a vent path. The recirculation loop will convert post-combustion gases into species that are acceptable to vent, remove water from the gas, and filter particles out of the gas by circulating the gases from the combustion chamber through processing canisters and back into the chamber until the bulk gas in the chamber is acceptable for venting through the space station vent system.

The current concept for these packages is that they can accomodate the entire science envelope. If however, it is determined that the package needs to be upgraded or modified, it will be able to be removed from the rack and replaced.

\section{Experiment Specific Hardware}

The combustion module provides an empty combustion chamber with standard interfaces and a set of standard diagnostics mounted around the chamber. As experiments are identified to use the FCF, additional hardware will be required to fully implement the science. Each experiment will need an EMS to mount within the combustion chamber and interface to the chamber. These EMS's may include hardware to ignite the fuel, hardware to deploy droplets, radiometers, thermistors, fuel holders, nozzles or trays, liquid fuel supplies or solid fuels, soot sampling mechanisms, hardware to seed gas or liquid phases for imaging purposes, or a pressure vessel in which to perform higher pressure combustion, such as for metals. Diagrams of EMSs for several different classes of experiments are shown in figures IV-4, IV-5 and IV-6.

Some investigations may require specific optical diagnostics that are not provided by the facility. The optical plate that surrounds the combustion chamber will have the capability to be reconfigured to support new types of optical diagnostics and the chamber windows, as mentioned above, will be replaced as needed.

\section{Software}

The SS FCF project will provide the majority of the software required. This software will reside on the VME bus systems, except in two cases. If there are specific control algorithms/software required that have been developed by the specific science investigation team which can be integrated with the facility software, these could be loaded into the VME bus system in the combustion rack; or if a controller is included in the experiment specific hardware, then the specific science investigation team would be responsible for software that would reside on the controller.

\section{E. Logistics Scenario:}

A logistics scenario is the concept for getting experiments to the space station, operating them in the FCF, and bringing the science results back to Earth. The current concept for getting experiments to the space station is as cargo aboard a space vehicle. Once on-orbit, an EMS would be installed into the Combustion 
Module by an astronaut. Installation of the EMS would include making all hardware connections with the FCF (e.g. power, data, vacuum/vent, nitrogen), verifying these connections, and performing functional check-out of the EMS including hardware and software. The astronaut would then install the experiment specific diagnostics, if necessary, around the chamber by making all hardware connections between the experiment specific diagnostics and the optical plate, verify these connections, and perform functional check-out of the experiment.

The operations of the experiments are very dependent on the experiment being performed. The concept for operations is to maximize the effectiveness of crew time by automating experiment functions when it is experimentally and technologically practical as well as cost efficient.

Resources which need replenishment will be planned for and the resupply of these will be negotiated with the ISSA and the resupply vehicle programs.

Experiments which are completed will be removed by an astronaut and packed for return to Earth in the appropriate carrier. Another EMS will be installed into the FCF chamber. This concept of continual resupply of experiments for the FCF will ensure that the NASA microgravity combustion science program has a consistent and constant onorbit platform for performing microgravity combustion science research.

\section{Breadboard Plans/Accomplishments}

The SS FCF Project is currently in the process of capturing all of the requirements that will have to be met. A necessary part of this phase is to demonstrate early in the life cycle of a project that systems can be designed to meet key performance parameters. This may include development of new technologies to meet these needs. Most often, this is addressed by breadboard testing of systems that potentially will be used in the final design. Two breadboards are currently in work and another is being planned by the SS FCF project. In addition, a number of other projects are currently performing breadboards that are associated with the specific type of science investigation. The SS FCF breadboards and a number of the breadboards external to the project are described below.

\section{A. Automated Fill}

There are two methods for supplying gases to the combustion chamber. One method involves bringing pre-mixed gases to the station and flowing them into the chamber. This limits the ability to change concentrations. The other option is to perform mixing of gases on orbit. This involves transporting pure gases, or nominal mixtures to orbit, and then mixing or adjusting the concentrations as needed for the test points. Since this provides the greatest flexibility, on-orbit mixing is the preferred method. In order to demonstrated the feasibility of on-orbit mixing to precise concentrations, the FCF project developed and tested an automated fill breadboard. This breadboard utilized the partial pressures method for mixing the gases. A flow meter was used to reduce the flow rate as pressure levels were reached, allowing for improved accuracy. An evaluation of the final mixture was made using a gas chromatograph. Results have shown accuracies of $1.2 \%$ of the smallest constituent (down to $4 \%$ ) in mixtures of helium and nitrogen. This technology can be extended to flight hardware.

\section{B. Liquid Vaporization}

A number of the diluents, including $\mathrm{CO}_{2}$ and $\mathrm{SF}_{6}$, that are planned to be used in the facility liquify at fairly low pressures. In order to minimize the volume of the gases that will be transported to the space station, it is desirable that these diluents be transported as room temperature liquids. This requires a method to allow them to retum to gas on orbit. This also requires that on orbit mixing be implemented. Breadboard tests are on going to prove methods to convert the liquids back into gases as they are being used. This breadboard expected to be completed by early 1995 .

\section{c. Exhauswent}

The combustion module utilizes the space station vent system to remove unused gases and products of combustion. The current requirements on what can be vented into the space station vent system are very restrictive. $A$ breadboard is planned to determine the feasibility and performance of various methods of processing the gases so that they meet the interface 
requirements on species and concentration. Some of the techniques to be evaluated are molecular sieves and catalytic oxidation. This testing will include actual combustion of candidate test points so that the products of combustion can be characterized before being processed. If this characterization is known from previous tests, then gas mixtures will be prepared to simulate the products of combustion.

\section{SS FCE Breadboard Summany}

Other breadboards, beyond those described above, may be identified and implemented during the next few years to reduce technical risk and demonstrate feasibility. One of the breadboards being considered is a breadboard to demonstrate high resolution video imaging that might be required for droplet type combustion experiments. There are also a number of breadboards being conducted for the fluids module that may have potential for use in the combustion module. One of these is called the Automated Positioning and Tracking (APT) breadboard. The APT breadboard is demonstrating that two orthogonal cameras with microscopic lenses can be used to image small features of interest, such as droplets, and track the motion of the feature. The system will be able to recognize a feature of interest, such as a droplet of fuel, determine the camera motion required to keep it within the field of view, translate the cameras while keeping the image in focus and retain image resolution, and maintain knowledge of the camera image relative to a fixed point of reference.

\section{E. External Breadboards}

There are currently a number of projects that fall into the SS FCF combustion science envelope that are also doing breadboard testing. Although the exact science may not be performed in the SS FCF, many of the techniques developed in the breadboards may be applicable, and will be adapted as necessary.

CM-1 The CM-1 project has performed a number of breadboards during the development phase. Silica gel, lithium hydroxide and hopcalite in processing products of combustion were characterized. The thermal effects of gas bottle discharge and pressurization of the combustion chamber was studied. The effect of microgravity on mass flow controllers was studied. The ability of soot sampler mechanisms to meet science requirements was demonstrated. Many of the diagnostics used by $\mathrm{CM}-1$ were also demonstrated to be acceptable for use in the Combustion Module.

Droplet Combustion Experiment(DCE) The DCE project has demonstrated the ability to deploy a droplet with minimal residual velocity and ignite it, which is critical to future microgravity droplet combustion experiments.

Spread Acress Liquids(SAL) The SAL project has demonstrated the use of a spaceflight operational color schlieren imaging system .

DABTfire The DARTfire project has demonstrated the capability to acquire video imaging data over a wide range of frequencies.

\section{E. LeBC Microgravity Combustion Advanced Diagnostics Work}

The Microgravity Combustion Advanced Diagnostics Group at LeRC is working to develop many of the advanced diagnostics techniques that may be required in the future. The FCF project will work closely with this group to transition techniques as they are developed into the combustion module. This group is pioneering such systems as rainbow schlieren imaging, gas phase particle imaging velocimetry and multipoint laser dopler velocimetry.

\section{Vl. Summany}

A conceptual design of a Combustion Module, which is part of the Space Station Fluids/Combustion Facility, has been presented. The concept was developed to maximize use of common hardware and software in order to minimize development time and effort for a large number of combustion science investigations, and to provide maximum scientific return.

These objectives are met through provision of standard interfaces which support like experimental investigations in a common combustion chamber with common diagnostics. The Combustion Module provide a maximum of common hardware and software with clearly defined interfaces and standard data acquisition and control capabilities.

The Combustion Module concept supports all of the classes of microgravity 
combustion scientific investigations currently envisioned by the Microgravity Combustion Discipline Working Group to be performed aboard the International Space Station Alpha.

\section{Beferences}

[1] Thompson, R. L., et al, "Conceptual Design for the Space Station Freedom Modular Combustion Facility", NASA TM 102037, January, 1990.

[2] NASA, "Space Station Freedom Modular Combustion Facility Assessment Workshop Proceedings", May 17-18, 1989.

[3] Rohn, D. W., Morilak, D.P., Rhatigan, J.L., and Peterson, T.T., "Conceptual Design of the Space Station Fluids Module", Second

Microgravity Fluid Physics Conference, 21-23

June, 1994. 


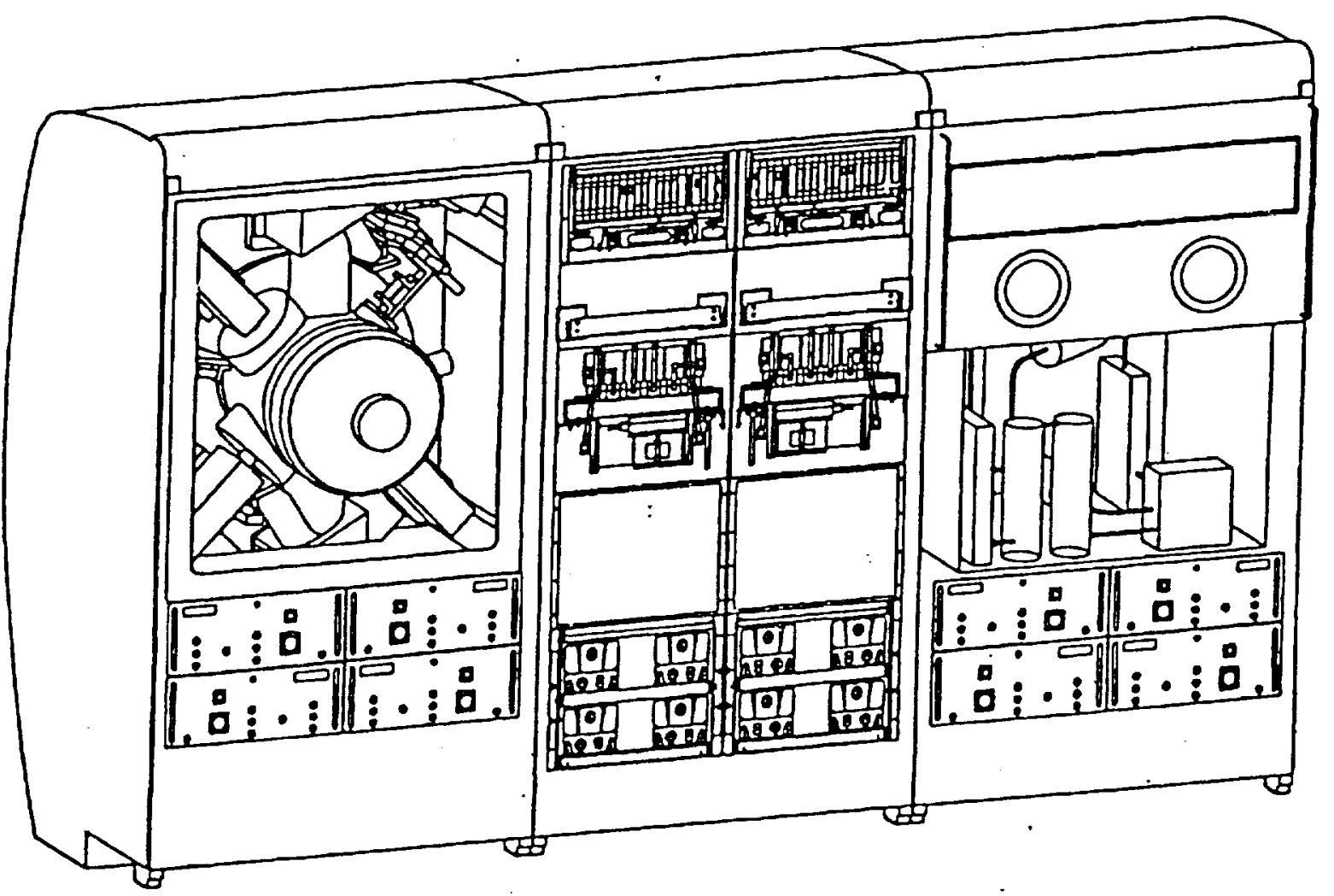

Figure IV-1 Space Station Fluids/Combustion Facility Concept

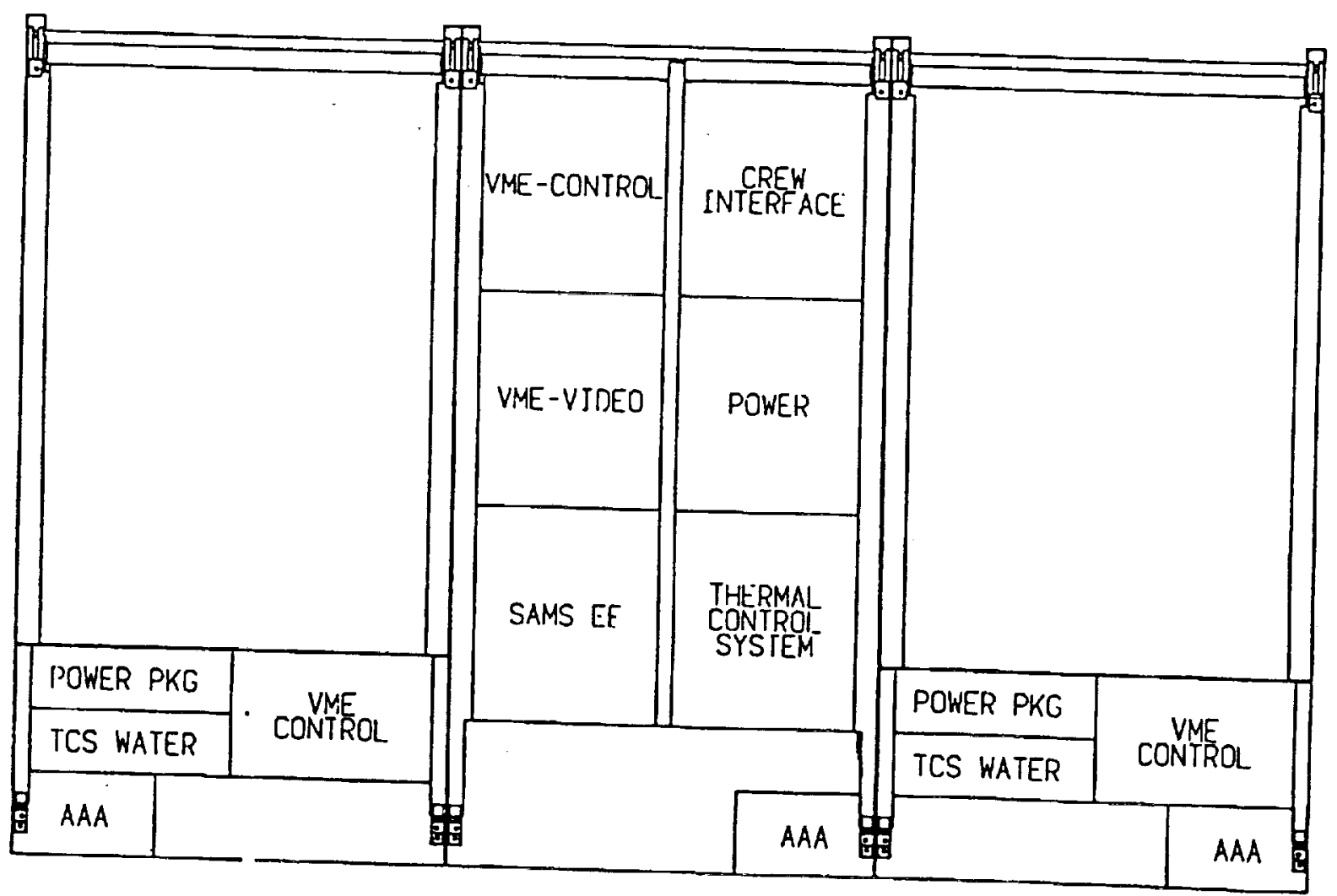

Figure IV-2 Core Systems Diagram 


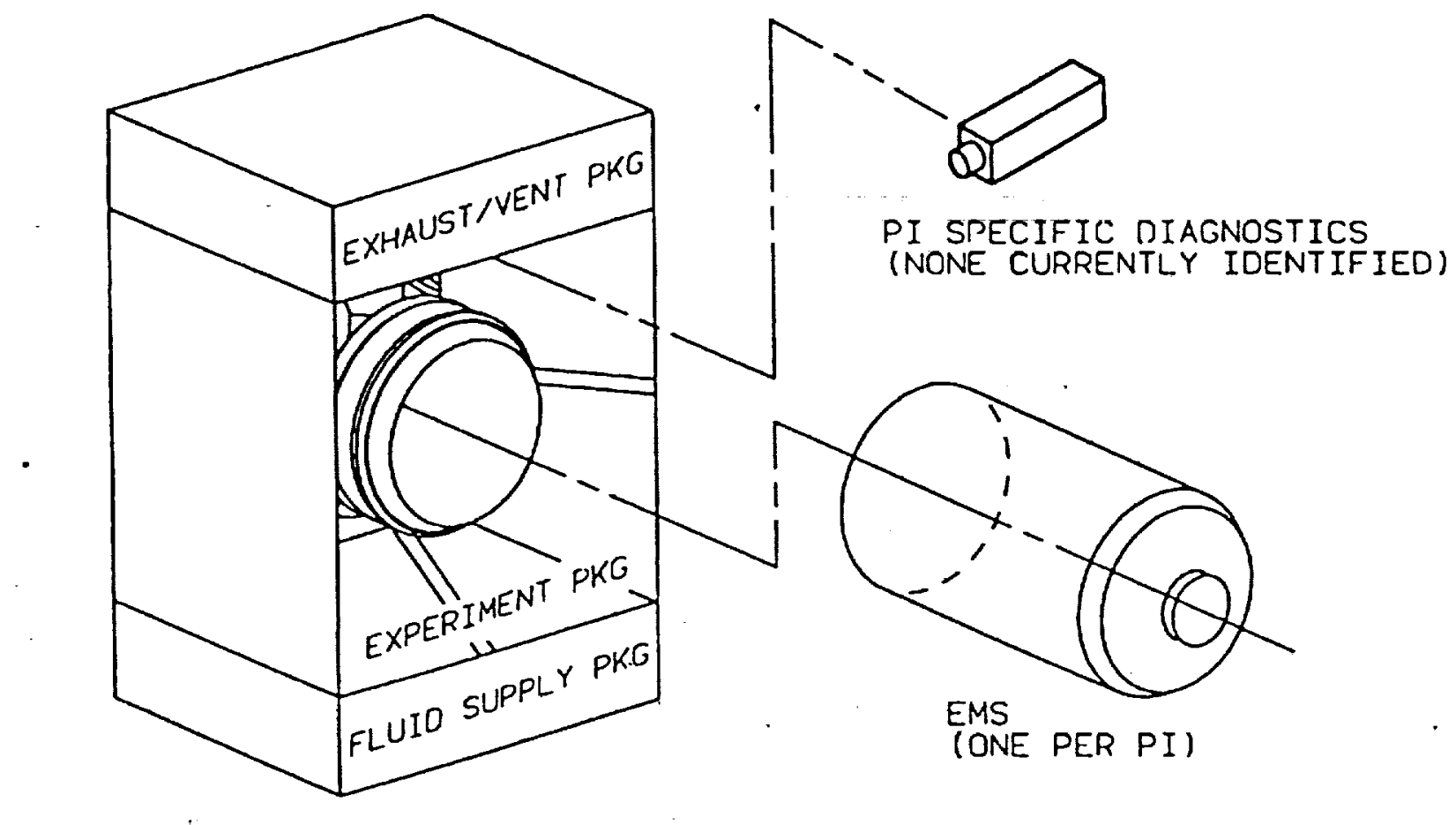

Figure IV-3 Combustion Module Diagram

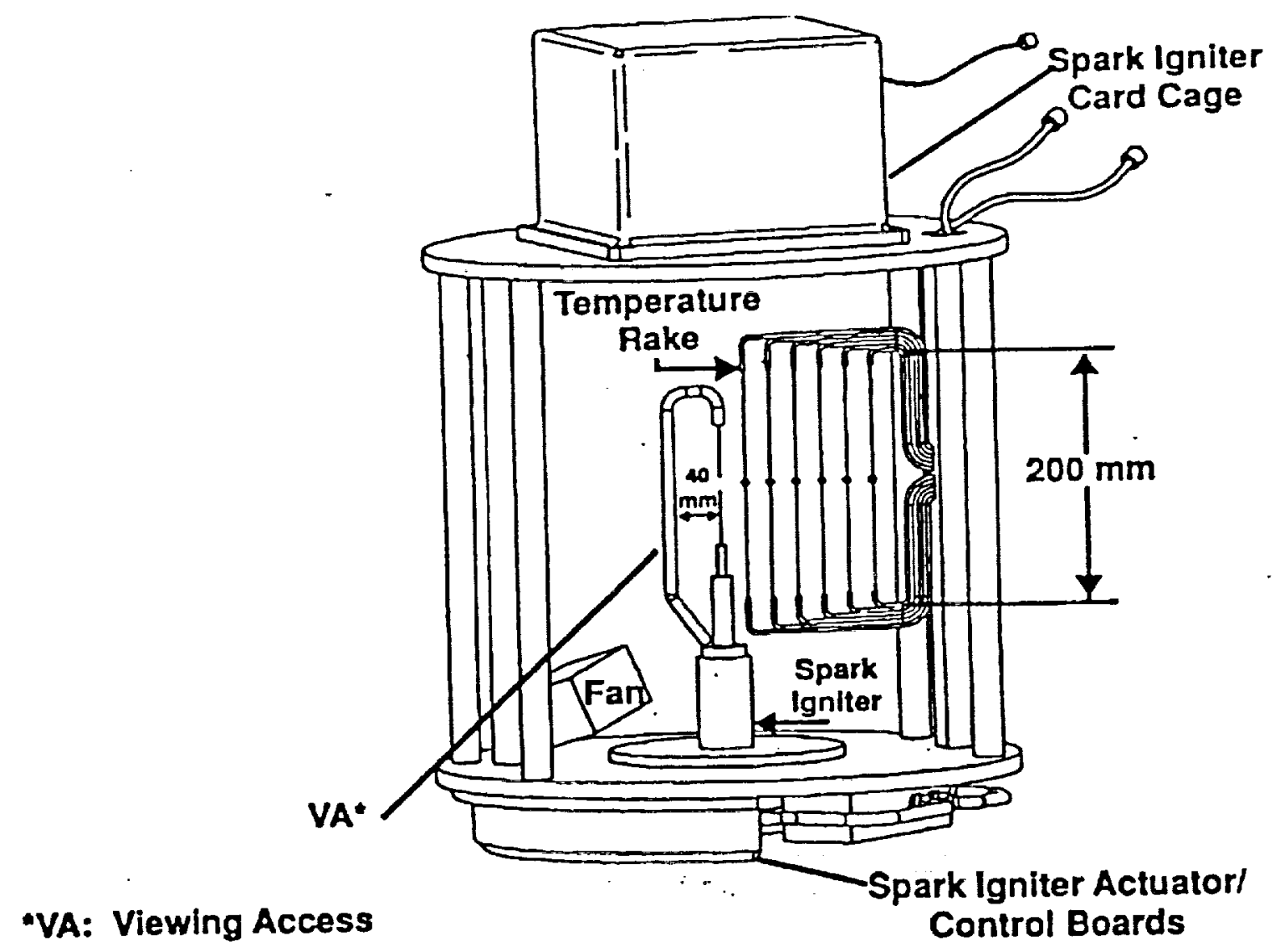

Figure IV-4 Structure of FlameBalls at Low Lewis Number Experiment Mounting Structure 
VA: Vlowing Access

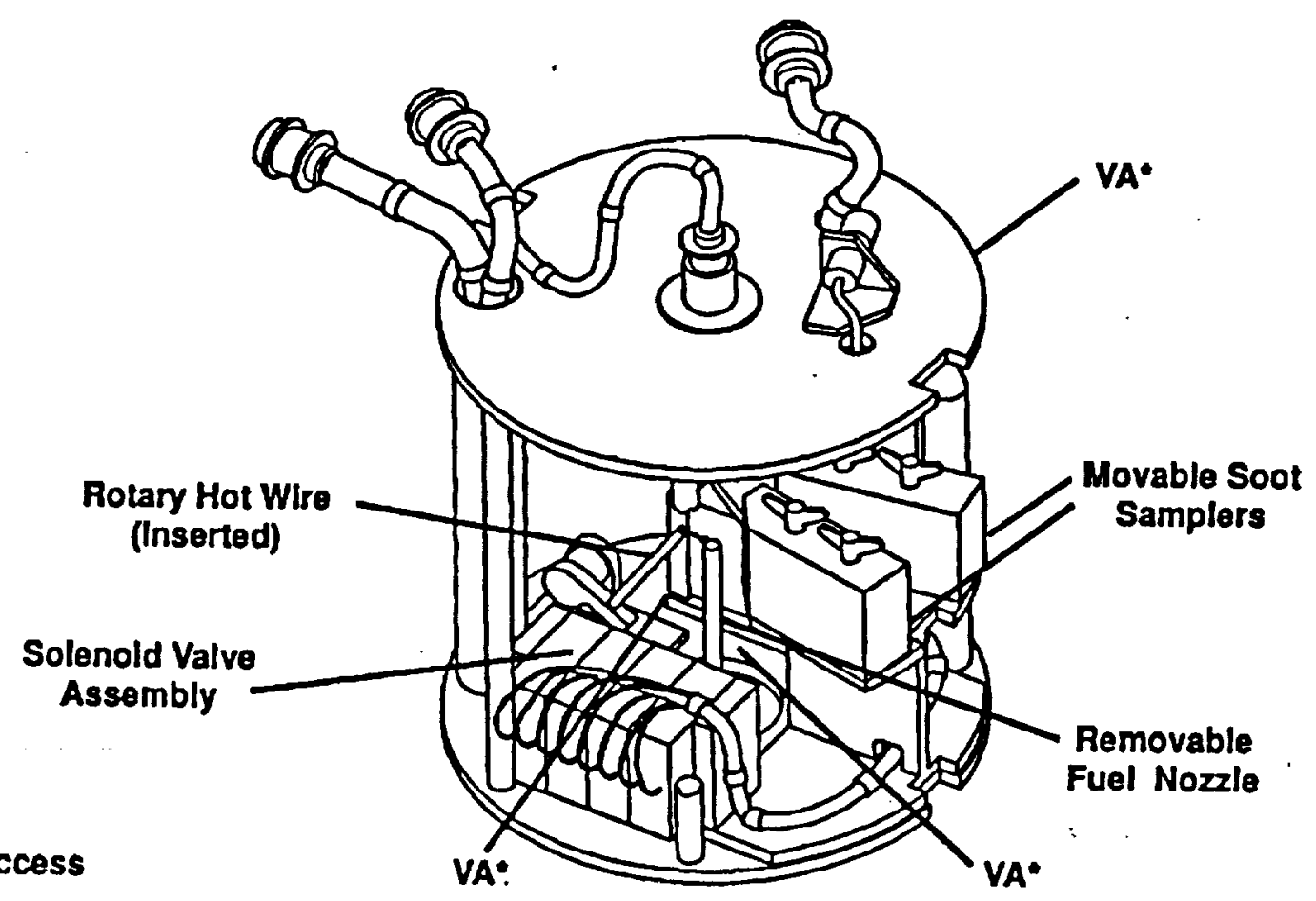

Figure IV-5 Laminar Soot Processes Experiment Mounting Structure

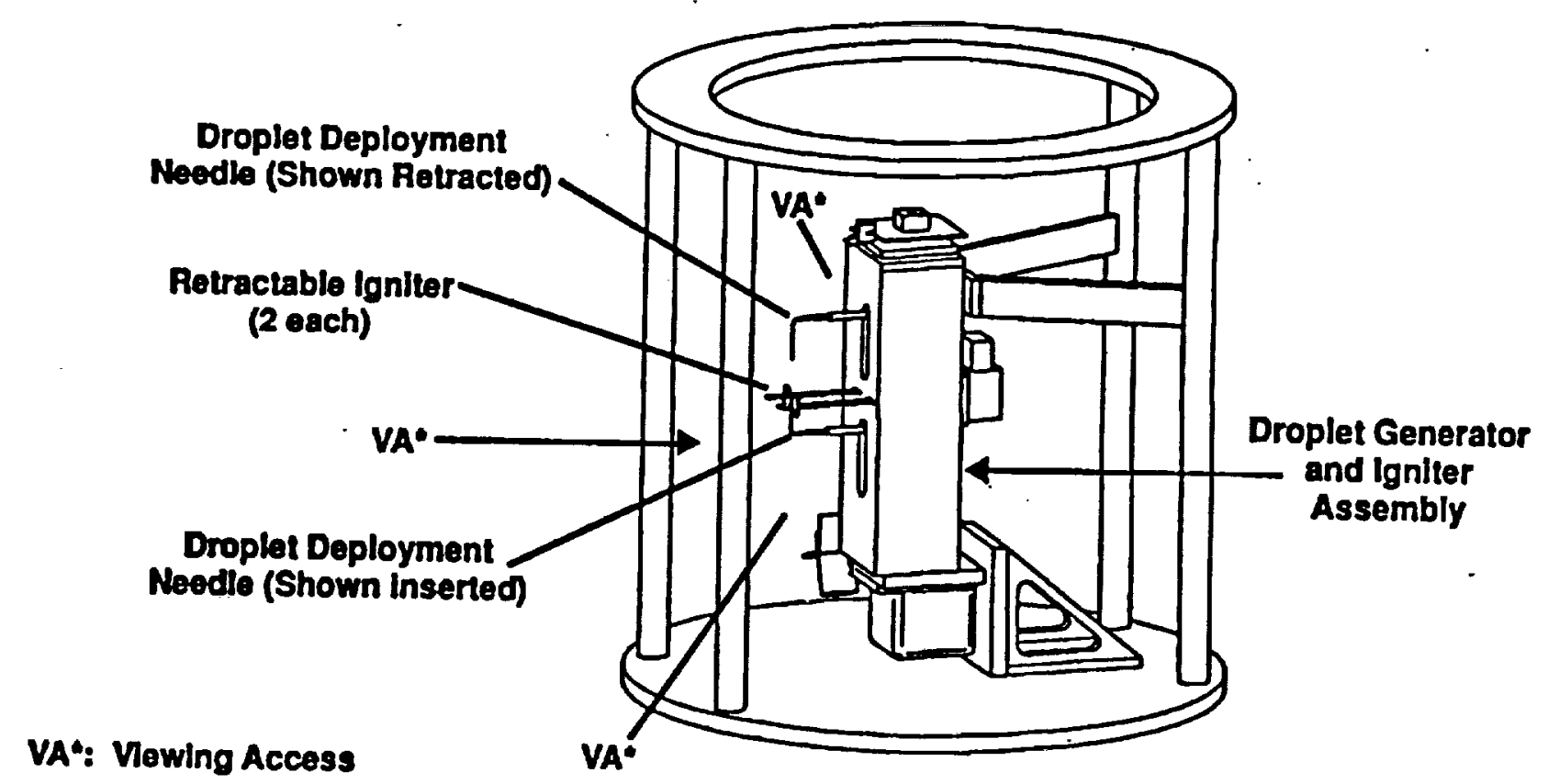

Figure IV-6 Droplët Combustion Experiment Mounting Structure 

gathering and maintaining the data needed, and completing and revewing to Washington Headquarters Services, Directorate for Inlormation Operations and Aeporrs. 2215 Jes. collection of information, including suggestions for reducing this burden, to Washinglon Heade Budget, Paperwork Reduction Prolect (0704-0188), Washington, DC 20503.

\begin{tabular}{l|l|l} 
Davis Mghway, Sulte 1204, Arlington. VA 22202-4302, and to the Office of Management and B. REPORT TYPE AND DATES COVERED
\end{tabular}
1. AGENCY USE ONLY (Leave blank)
November 1994
4. TITLE AND SUBTITLE
Conceptual Design of the Space Station Combustion Module

5. FUNDING NUMBERS

AUTHOR(S)

Daniel P. Morilak, Dennis W. Rohn, and Jennifer L. Rhatigan

7. PERFORMING ORGANIZATION NAME(S) AND ADDRESS(ES)

8. PERFORMING ORGANIZATION

REPORT NUMBER

National Aeronautics and Space Administration

Lewis Research Center

E-9244

Cleveland, Ohio 44135-3191

9. SPONSORING/MONITORING AGENCY NAME(S) AND ADDRESS(ES)

National Aeronautics and Space Administration

Washington, D.C. 20546-0001

WU-None

10. SPONSORING/MONITORING

AGENCY REPORT NUMBER

NASA TM- 106788

AIAA-95-0692

11. SUPPLEMENTARY NOTES

Prepared for the 33rd Aerospace Sciences Meeting and Exhibit sponsored by the American Institute of Aeronautics and Astronautics, Reno, Nevada, January 9-12, 1995. Responsible person, Daniel P. Morilak, organization code 6724, (216) 433-3412.

12a. DISTRIBUTIONAVAILABILITY STATEMENT

Unclassified -Unlimited

Subject Category 15

13. ABSTAACT (Maximum 200 words)

The purpose of this paper is to describe the conceptual design of the Combustion Module for the International Space Station Alpha (ISSA). This module is part of the Space Station Fluids/Combustion Facility (SS FCF) under development at the NASA Lewis Research Center. The Fluids/Combustion Facility is one of several science facilities which are being developed to support microgravity science investigations in the US Laboratory Module of the ISSA. The SS FCF will support a multitude of fluids and combustion science investigations over the lifetime of the ISSA and return state-of-theart science data in a timely and efficient manner to the scientific communities. This will be accomplished through modularization of hardware, with planned, periodic upgrades; modularization of like scientific investigations that make use of common facility functions; and through the use of orbital replacement units (ORUs) for incorporation of new technology and new functionality. The SS FCF is scheduled to become operational on-orbit in 1999. The Combustion Module is presently scheduled for launch to orbit and integration with the Fluids/Combustion Facility in 1999. The objectives of this paper are to describe the history of the Combustion Module concept, the types of combustion science investigations which will be accommodated by the module, the hardware design heritage, the hardware concept, and the hardware breadboarding efforts currently underway.

\section{SUBJECT TERMS}

Microgravity; Combustion; Space station facilities

16. PRICE CODE

A03

\begin{tabular}{|c|c|}
\hline $\begin{array}{c}\text { 17. SECURTYY CLASSIFICATION } \\
\text { OF REPORT } \\
\text { Unclassified }\end{array}$ & $\begin{array}{c}\text { 18. SECURITY CLASSIFICATION } \\
\text { OF THIS PAGE } \\
\text { Unclassified }\end{array}$ \\
\hline
\end{tabular}

19. SECURITY CLASSIFICATION OF ABSTRACT Unclassified 


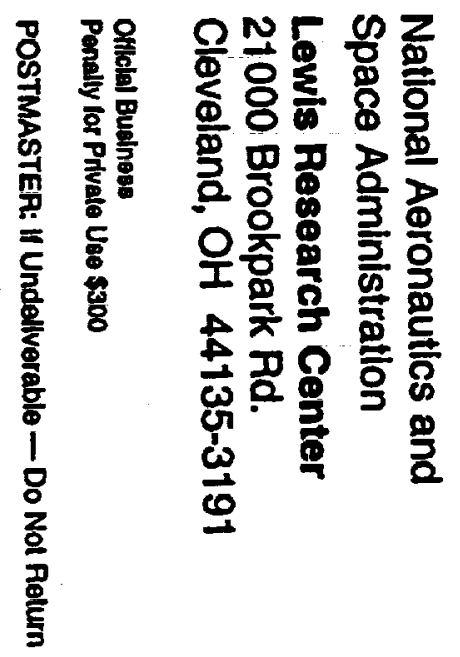


